\title{
Joko Widodo Dalam Bingkai Harian Umum Republika
}

\author{
Suharyo \\ Fakultas Ilmu Budaya, Universitas Diponegoro, Semarang \\ Email: haryo.sastra@gmail.com
}

\begin{abstract}
This study aims to describe how the daily Republika frames President Joko Widodo. To disclose, simak method followed by noting technique - as described by Sudarjanto (1993) - will be used, while the framing model by Pan Kossicki will be used for the analysis. As a result, President Joko Widodo is positively framed through (a) a syntactic structure that includes the title diction he chooses, leads, backgrounds, source uses, and positive news cover; (B) structure of the script making full use of the $5 \mathrm{~W} 1 \mathrm{H}$ element, (3) the thematic structure seen through President Joko Widodo's message which is packed with a polite diction, such as "the student should focus more on the more productive use of energy, such as"; And (4) rhetorical structure seen through the photo placement of Joko Widodo increasingly clarify the message that wants to be delivered by Jokowi.
\end{abstract}

Keywords: Joko Widodo, framing, Pan Kosicki model, Republika

\section{Intisari}

Penelitian ini bertujuan untuk mendeskripsikan bagaimana harian umum Republika dalam mem-frame Presiden Joko Widodo. Untuk mengungkapnya digunakan metode simak dan dilanjutkan dengan teknik catat sebagaimana dipaparkan oleh Sudarjanto (1993), sedangkan analisis menggunakan analisis framing model Pan Kossicki. Hasilnya, Presiden Joko Widodo di-frame secara positif melalui (a) struktur sintakasis yang meliputi diksi judul yang dipilihnya, lead, latar, penggunaan sumber, dan penutup berita secara positif; (b) struktur skrip dengan memanfaatkan secara lengkap unsur $5 \mathrm{~W}$ 1H;, (3) struktur tematik yang terbaca melalui pesan Presiden Joko Widodo yang dikemas dengan diksi yang santun, seperti "mahasiswa sebaiknya lebih fokus pada pengguanaan energi yang lebih produktif,seperti"; dan (4) struktur retoris melalui penempatan foto Joko Widodo semakin memperjelas pesan hang ingin disampaikan Jokowi.

Kata Kunci: Joko Widodo, framing, model Pan Kosicki, Republika 


\section{Pendahuluan}

Penelitian ini dilatarbelakangi oleh perbedaan pemahaman realitas antara kaum positivisme yang menganggap bahwa realitas itu bersifat objektif, ada, dan independen; sedangkan kaum konstruksionis justru sebaliknya yaitu bahwa realitas itu bersifat subjektif dan berpihak karena sudah dikonstruksi oleh berbagai macam kepentingan (politik, ekonomi, sosial, dan budaya). Salah satu realitas tentang peristiwa kematian Presiden Lee Kuan Yew beberapa waktu yang lalu, misalnya, harian Kompas menulis dengan judul "Lee Kuan Yew Wariskan Singapura yang Maju”, sedangkan Suara Merdeka menulis judul “ Lee Kuan Yew Terapkan Tangan Besi, Miliki Kesamaan dengan Soeharto". Dari sini, tampak bahwa dari peristiwa yang sama melahirkan pandangan/frame yang berbeda. Kompas memandang secara "positif" dalam mengkonstruksi peristiwa kematian Presiden Singapura tersebut. Akan tetapi, harian Suara Merdeka mengkonstruksinya secara "negatif". Bahkan menyejajarkan dengan Presiden Saoeharto. Lalu, bagaimana halnya dengan berita yang menyangkut Pemerintahan Jokowi yang dimuat di harian Republika? Tulisan ini mencoba menjelaskannya melalui analisis framing model Pan Kosicki.

Penelitian yang menggunakan ancangan framing sudah banyak dilakukan. Misalnya, penelitian Hasfi, (2011); penelitian Flora, (2014); penelitian Karman, (2013); peneleitian Putera, (2013); dan penelitian Suharyo, dkk., (2013). Menurut hasil penelitian mereka bahwa berita di media massa sudah dikonstruksi sedemikian rupa sebagai komoditas politik, ekonomi, dan sosial budaya. Menurut mereka, realitas (yang ditulis di media massa) bukanlah fakta yang sebenarnya, tetapi sudah di-frame oleh wartawan sesuai dengan kepentingan tertentu. Dalam hal ini, pembaca juga telah “digiring" untuk memahami realitas (semu) tersebut yang telah dibingkai oleh media massa. Lebih lanjut, pemahaman terhadap realitas tersebut atau dengana kata lain pemaknaan realitas tergantung pada media massa mana yang membingkainya. Jadi, sesungguhnya pembaca telah "terperangkap" oleh konstruksi yang dibuat oleh media massa.

Meskipun sudah banyak penelitian dengan menggunakan ancangan framing sebagaimana dipaparkan secara ringkas di atas, penelitian ini selalu saja menarik untuk 
dilakukan karena objek penelitian analisis framing selalu seiring dengan "rezim", "kekuasaan", dan "kepentingan” yang selalu dinamis.

Teori framing (Eriyanto, 2012; Muslich, 2008) memandang bahwa (1) fakta atau peristiwa merupakan hasil konstruksi subjektif yang tercipta lewat konstruksi, sudut pandang tertentu si wartawan, (2) media merupakan agen konstruksi sosial yang mendefinisikan realitas, (3) berita bukan refleksi dari suaatu realitas, tetapi hanya konstruksi dari realitas. Berita tak ubahnya seperti sebuah drama. Ia bukan realitas, tetapi potret dari arena pertarungan antarberbagai kelompok kepentingan (organisasi, politik, sosial, dll.), (4) berita bersifat subjektif (5) wartawan bukan pelapor, tetapi ia agen konstruksi realitas, (6) etika, nilai, pilihan moral, keberpihakan wartawan, (7) nilai, etika, dan pilihan moral peneliti menjadi bagian integral dalam penelitian karena peneliti adalah entitas dengan berbagai nilai dan keberpihakan yang berbeda-beda, (8) khalayak pembaca memiliki penafsiran sendiri terhadap berita karena makna suatu teks bukan terdapat dalam pesan/teks/berita tersebut, tetapi makna yang terkandung/dilakukan secara dialektis oleh pembaca secara dinamis dan polisemis (sifatnya).

\section{Metode Penelitian}

Untuk menjawab pertanyaan penelitian ini, penulis memilih harian Republika yang terbit tahun 2016 sebagai sumber datanya. Dari sumber tersebut, pengumpulan data dilakukan melalui metode simak dan teknik catat dengan langkah: (1) mengambil berita yang aktual, (2) mengamati dengan cermat isi beritaa tersebut baik diksi, kata, kalimat, dan struktur kalimat, maupun konteksnya. Dari hasil penyimakan tersebut, langkah berikutnya adalah mencatat data tersebut ke dalam kartu-kartu data. Tahap analisis data menggunakan analisis framing model Pan Kosicki ( Erianto, 2012) seperti ditampilkan berikut ini. 
Skema 1 Kerangka Analisis Framing Pan dan Kosicki

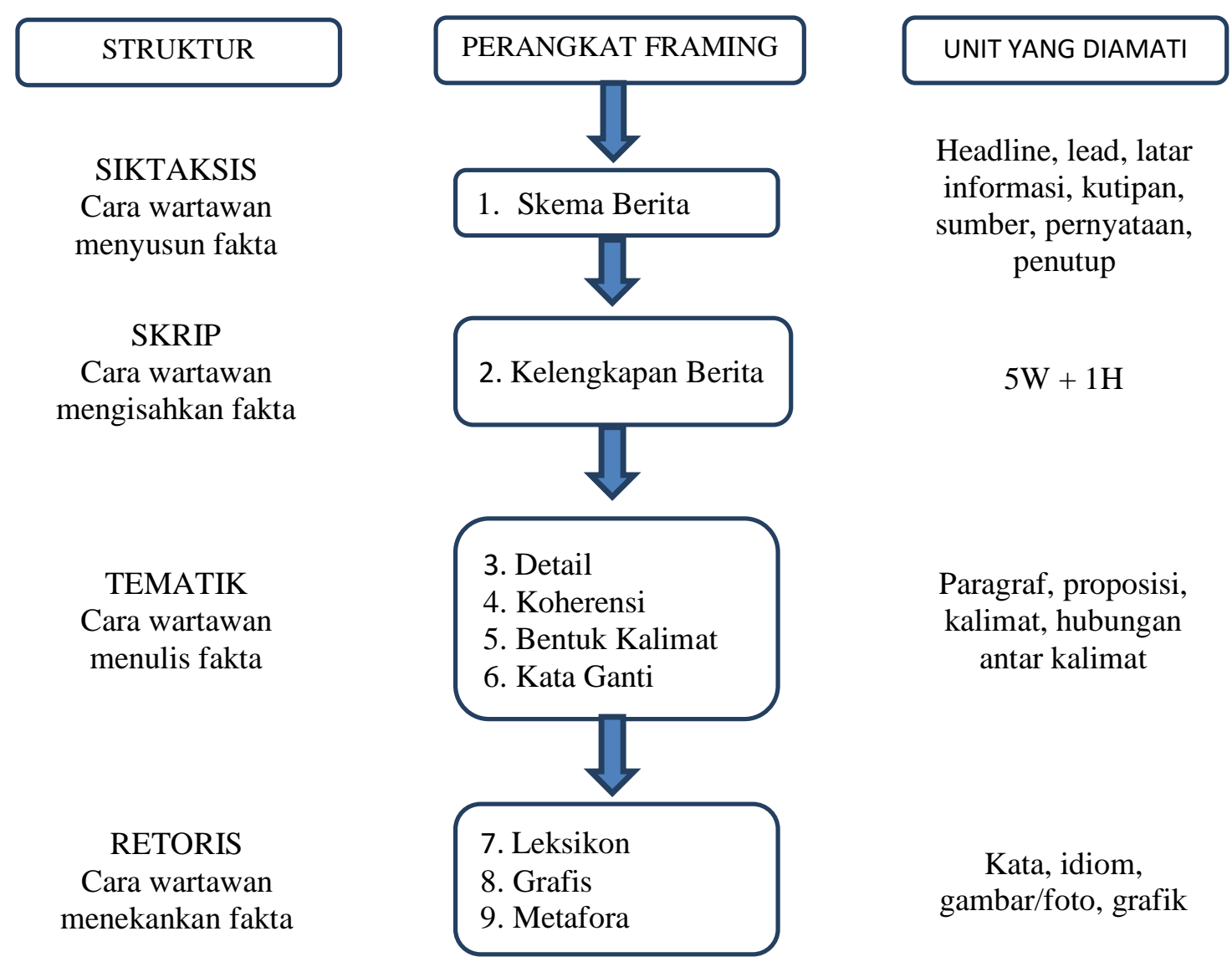

\section{Pembahasan}

Data dalam penelitian ini dianalisis dengan menggunakan analisis framing model Pan dan Kosicki. Pan dan Kosicki dalam menganalsis berita menjadi ke dalam empat struktur, yaitu (1) struktur sintaksis, (2) struktur skrip, (3) struktur tematik, dan (4) struktur retoris. Data sampel dalam tulisan ini diambil dari berita harian Republika, 16 Mei 2017 dengan judul “Jokowi Minta Sesama Anak Banagsa Jangan Saling Hujat”. Hasilnya dipaparkan di bawah ini.

\section{Struktur Sintaksis}

Dari judul berita "Jokowi Minta Sesama Anak Bangsa Jangan Saling Menghujat"menunjukkan bahwa saat ini sesama generasi muda bangsa sedang mengalami problem, yaitu adanya saling hujat-menghujat sehingga Jokowi selaku 
Presiden meminta menghentikannya. Sementara itu, dari segi penulisan, tidak menampilkan tanda baca titik dua pada judul. Republika menggunakan diksi kata minta untuk menyampaikan pesan Jokowi sehingga terasa lebih halus makna yang disampaikan.

Pada unsur lead, memberitakan bahwa Jokowi menyesalkan anak muda sekarang yang lebih senang demonstrasi yang dinilainya kegiatan yang tidak produktif. Di samping itu, diberitakan bahwa Jokowi semakin sedih lantaran anak muda saat ini menggunakan media sosial untuk "menyerang" satu sama lain. Hal itu tampak pada kutipan berita berikut.

Presiden Joko Widodo (Jokowi) menyesalkan anak muda Indonesia yang lebih senang turun ke jalan. Menurut dia, demonstrasi merupakan aktivitas tidak produktif. Dia semakin sedih lantaran ada muda menggunakan media sosial (medsos) untuk kegiatan saling serang satu sama lain.

Dilihat dari ari latar informasi, republika.com menuliskan bahwa Jokowi menyesalkan tindakan anak muda saat ini yang senang demonstrasi, sehingga Jokowi juga merasa sedih lantaran adanya demo yang terjadi setiap hari. Oleh karena itu, Jokowi ingin anak muda saat ini berpikir ke depan yang lebih produktif.

Ada hal yang menarik pada bagian latar, yaitu harian Republika menyampaikan pernyataan Jokowi yang menegur Menteri Susi Pudjiastuti karena masih mengurus cantrang bertahun-tahun. Padahal negara lain sudah mengurus offshore aquaculture. Artinya, melalui latar informasi tersebut, republika.com menyampaikan bahwa tidak hanya kepada anak muda saja yang diharapkan berpikir ke depan, tetapi juga para anak buahnya, dan umumnya masyarakat Indonesia. Pada bagian pentup, Republika memberitakan tentang rasa senang PMII pada Jokowi karena aselama ini belum pernah dihadiri oleh presiden-preseden sebelumnya, seperti tampak pada kutipan berikut.

Ketua Umum PB PMII Aminuddin Ma'ruf menyampaikan rasa bangganya perhelatan kongres dibuka Presiden Jokowi. Menurut Aminuddin, dalam sejarah PMII, baru dua kali presiden membuka kongres. "Presiden Sukarno pada kongres tahun 1963 dan Pak Jokowi dalam kongres ke-19 kali," ujarnya. 


\section{Struktur Skrip}

Dari sisi skrip, berita ini menampilkan unsur 5W saja. Unsur pertama yaitu who, siapa yang berpesan dalam berita dan ditujukan kepada siapa pesan tersebut. Berikutnya unsur what yaitu apa pesan yang disampaikan Jokowi. Selanjutnya yaitu unsur where dan when yaitu di mana Jokowi menyampikan pesan dan pada tanggal berapa. Terakhir yaitu unsur why yang berisi tentang mengapa Jokowi mengingatkan agar generasi muda jangan hanya senang berdemo, seperti disajikan pada kutipan berikut.

"Saya sedih setiap hari ada ratusan, ribuan, ratusan ribu demo. Energi kita habis untuk itu, jangan saling menghujat, jangan saling menjelekkan, jangan saling memfitnah. Kita ini saudara, baik sesama Muslim, baik sebagai saudara sebangsa dan setanah air. Ini betul- betul tak produktif, habis energi kita untuk hal hal seperti itu," ujar Jokowi saat membuka Kongres XIX Pergerakan Pemuda Islam Indonesia (PMII) di Masjid Agung Kota Palu, Selasa (16/5).Menurut Jokowi, tidak seharusnya anak muda lebih senang menggelar aksi hanya untuk menyampaikan pendapat. Dia mengingatkan, kalau generasi muda hanya senang berdemo maka dipastikan tertinggal dengan negara lain.Karena itu, Jokowi berpesan kepada pengurus PMII untuk tidak terjebak ke dalam kegiatan yang tak produktif. Dia juga menyeru agar anggota PMII tidak hanya berkeinginan menjadi politisi dalam meniti karier ke depannya.

\section{Struktur Tematik}

Tema dalam berita hanya ada satu, yaitu pesan yang disampaikan Jokowi dalam Pembukaan Kongres PMII di Palu, sebagaimana dimuat pada bagian judul dan isi berita. Tidak satupun ditemukan kalimat yang berbeda dengan tema.Sementara pada unsur koherensi, berita yang disajikan memiliki koherensi penjelas dan sebab-akibat. Koherensi penjelas ditandai dengan kata "dan", sedangkan koherensi sebab-akibat, seperti ditunjukkan pada petikan berita berikut iini.

"Saya sedih setiap hari ada ratusan, ribuan, ratusan ribu demo. Energi kita habis untuk itu, jangan saling menghujat, jangan saling menjelekkan, jangan saling memfitnah. Kita ini saudara, baik sesama muslim, baik sebagai saudara sebangsa dan setanah air. Ini betul- betul tak produktif, habis energi kita untuk hal hal seperti itu," ujar Jokowi saat membuka Kongres XIX Pergerakan Pemuda Islam Indonesia (PMII) 
di Masjid Agung Kota Palu, Selasa (16/5). Karena itu, Jokowi berpesan kepada pengurus PMII untuk tidak terjebak ke dalam kegiatan yang tak produktif. Dia juga menyeru agar anggota PMII tidak hanya berkeinginan menjadi politisi dalam meniti karier ke depannya.

\section{Struktur Retoris}

Struktur retoris berupa gambar yaitu foto Jokowi yang sedang berpidato. Foto tersebut disajikan untuk mendukung isi berita tentang dirinya. Sementara itu, dari unsur leksikon terdapat kata-kata yang menonjol, yaitu frasa saling menghujat, menyesalkan, sedih, tidak terjebak, dan rasa bangga. Ketiga leksikon pertama mennggambarkan sikap Jokowi melihat fenomena anak-anak muda yang sering berdemo akhir-akhir kini, sedangkan leksikon rasa bangga mewakili perasaan ketua PMII atas kedatanagan Jokowi yang selama ini pada acara kongres PMII belum pernah dihadiri oleh presidenpresiden sebelumnya. Dari penjelasan di atas, secara ringkas dapat disajikan dalam tabel berikut ini.

Skema 2 Struktur Retoris Joko Widodo dalam Bingkai Harian Umum Republika

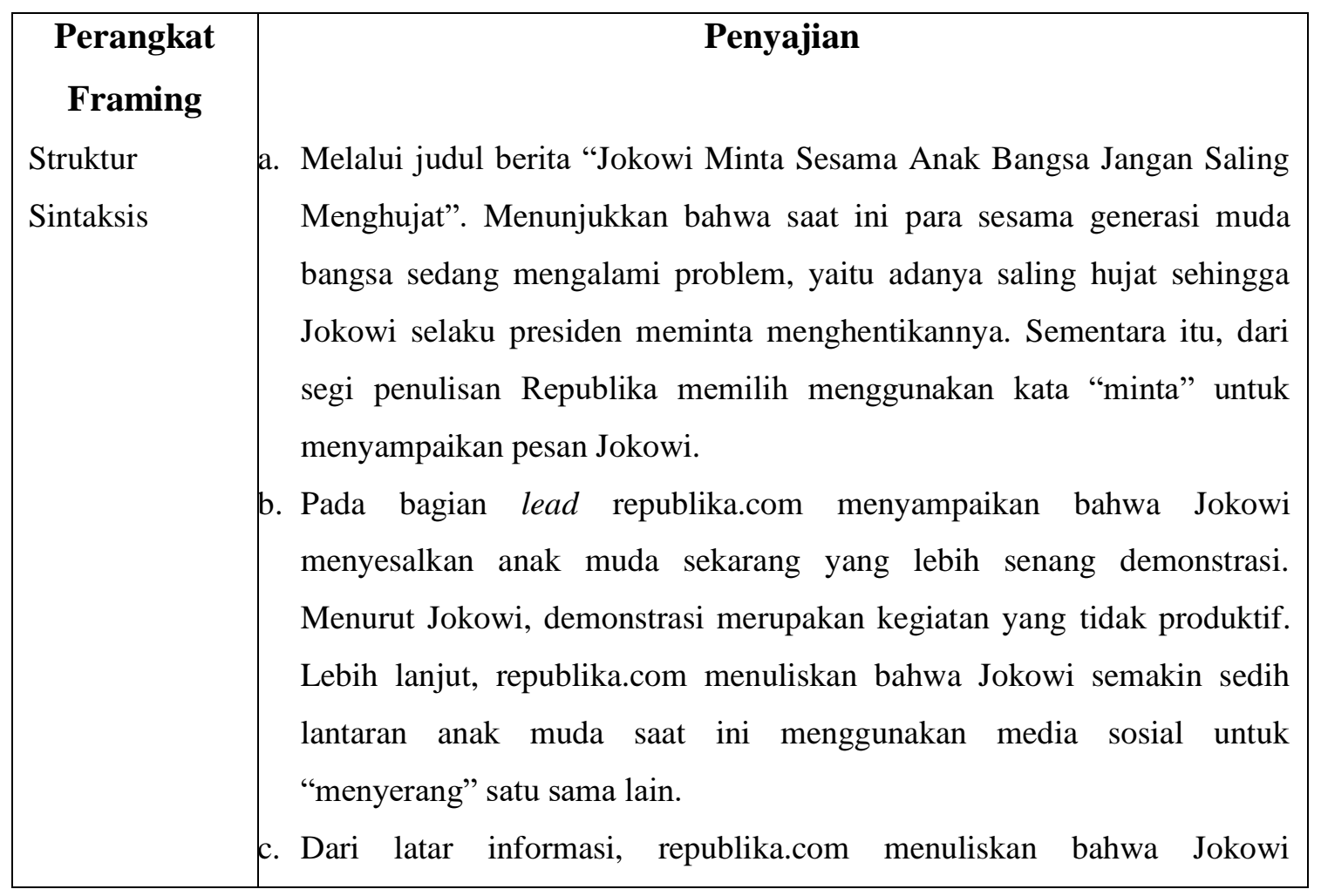




\begin{tabular}{|c|c|}
\hline & $\begin{array}{l}\text { menyesalkan tindakan anak muda saat ini yang senang demonstrasi. } \\
\text { Selain itu, Jokowi juga sedih lantaran adanya demo yang terjadi setiap } \\
\text { hari. Republika.com juga menuliskan bahwa Jokowi ingin anak muda saat } \\
\text { ini berpikir ke depan, tidak hanya memikirkan itu-itu saja yang dalam } \\
\text { berita disebutkan dengan istilah berdemo. } \\
\text { d. Berikutnya dari sumber pernyataan, republika.com menyajikan } \\
\text { pernyataan dari Jokowi dan Ketua Umum PMII, Aminuddin Ma'ruf. } \\
\text { e. Terakhir di bagian penutup, republika.com menulis pernyataan } \\
\text { Aminuddin Ma'ruf, yaitu dirinya bangga selaku ketua PMII sebab Jokowi } \\
\text { selaku presiden membuka langsung kongres organisasi tersebut. Menurut } \\
\text { Aminuddin, baru dua kali seorang presiden membuka kongres PMII, } \\
\text { terakhir kali pada tahun } 1963 \text { oleh Presiden Soekarno. }\end{array}$ \\
\hline Struktur Skrip & Unsur how tidak tersaji dalam berita. \\
\hline & $\begin{array}{l}\text { Tema dalam berita hanya ada satu, yaitu pesan yang disampaikan Jokowi } \\
\text { dalam Pembukaan Kongres PMII di Palu, sebagaimana dimuat pada bagian } \\
\text { judul dan isi berita. Tidak satupun ditemukan kalimat yang berbeda dengan } \\
\text { tema. } \\
\text { Dari unsur koherensi, terdapat koherensi sebab-akibat dan penjelas. }\end{array}$ \\
\hline $\begin{array}{l}\text { Struktur } \\
\text { Retoris }\end{array}$ & $\begin{array}{l}\text { Berita yang disajikan menampilkan struktur retoris berupa foto Jokowi yang } \\
\text { sedang berpidato. Sementara itu untuk leksikon terdapat kata-kata yang } \\
\text { menonjol, yaitu saling menghujat, menyesalkan, sedih, tidak terjebak, dan } \\
\text { rasa bangganya. }\end{array}$ \\
\hline
\end{tabular}

\section{Simpulan}

Dari uraian di atas, dapat disambil simpulan bahwa Presiden Jokowi oleh harian Republika di-frame secara positif. Hal itu tampak dari melalui (a) struktur sintakasis yang meliputi diksi judul yang dipilihnya, lead, latar, penggunaan sumber, dan penutup berita secara positif; (b) struktur skrip dengan memanfaatkan cukup lengkap unsur $5 \mathrm{~W}$ 1H;, (3) struktur tematik yang terbaca melalui pesan Presiden Joko Widodo yang dikemas dengan diksi yang santun, seperti "mahasiswa sebaiknya lebih fokus pada pengguanaan energi yang lebih produktif"; dan (4) struktur retoris melalui penempatan foto Joko semakin memperjelas pesan yang ingin disampaikannya. 


\section{Daftar Pustaka}

Eriyanto.2012. Analisis Framing: Konstruksi, Ideologi, dan Politik Media (Cet.ke-3). Yogyakarta: LKIS.

Flora,Elina. 2014. Analisis Framing Berita Calon Presiden RI 2014 - 2019 Pada Surat Kabar Kaltim Post dan Tribun Kaltim. Kalimantan Timur: Universitas Mulawarman.

Hasfi, Nurul. 2011. Analisis Framing Pemberitaan Malinda Dee di Detikcom Majalah Tempo dan Metro TV. Semarang: Universitas Diponegoro.

Karman.2013. "Media Massa dan Kontruksi Realitas (Analisis framing terhadap Pemberitaan SKB tentang Ahamdiyah di Indonesia pada Surat Kabar Harian Suara Pembaruan dan Republika" dalam Jurnal Studi Komunikasi dan Media, Vol.17 (Juli-Desember 2013).

Muslih, Masnur. 2008. "Kekuasaan Media Massa Mengonstruksi Realitas”. Jurnal Bahasa dan Seni tahun 36 no.2 Agustus 2008.

Putera, Ghanes Eka. 2014. Bingkai Media Terhadap Pemberitaan Capres Jokowi Pada Pilpres 2014 (Analisis Framing Media Online Kompas.Com dan Detik.Com). Semarang: Universitas Diponegoro.

Sudarjanto.1993. Metode dan Aneka Teknik Penelitian Linguistik. Yogyakarta: Gadjahmada University Press.

Suharyo, dkk. 2013. "Bahasa dan Kekuasaan: Antara Pertarungan Wacana dan Perebutan Kekuasaan (Studi Kasus Perilaku Politisi di Media Massa”. Semarang: Laporan Penelitian. 